\title{
Current Trends in the College Reserve Room
}

Dr. Lansberg is a member of the staff of the H.W.Wilson Company.

$\mathrm{T}$ HE PROBLEM of the reserve room is essentially an educational one. The procedures which are followed at each college or university are determined largely by the size of the institution, its educational policy, and the degree of library-faculty cooperation. No solution to the problem could or should be made in a vacuum-that is to say, the administrator, the teacher and the librarian should work together to evolve a program which will be satisfactory to all.

Both librarians and teachers have long expressed dissatisfaction with the reserve book system. One of the most outspoken critics of the reading habits of the American undergraduate and of "required reading" in particular was Wilhelm Munthe. ${ }^{1}$ Two college presidents, Henry M. Wriston ${ }^{2}$ of Brown University and Carter Davidson of Knox College, have echoed the views of the visitor from Oslo. Dr. Davidson summarizes the situation as follows:

Some teachers, however, find the textbook insufficient or impossible and supplement or replace it with several texts and a few source books kept on a "reserve shelf" behind the circulation desk. Here the student finds a chapter assigned in each volume and reads it under the pressure of time and confusion in the so-called reading room. The usual story of book use in this procedure is that

1 Munthe, Wilhelm. American Librarianship from a European Angle: An Attempt at an Evaluation of Policies and Activities. Chicago, American Library Association 1939 , p. 104-07,

2 Wriston, H. M. "College and University Libraries." In Danton. Emily M.. ed. The Library of Tomorrow: A Symposium, p. 146-47. Chicago, American Library Association, 1939 . each volume has a score of well-thumbed and dirty pages, the rest of the book remaining virgin. This is the favorite method of the social sciences. But the instructors must not fool themselves. Reports from my own librarian tell me that 16 per cent of all the books kept on reserve this year were not used at all by students and that $5 \mathrm{I}$ per cent were used less than five times in the year. What has been gained by keeping these books on reserve to compensate for the loss of taking them from the stacks? The reserve-shelf method often requires the purchase of several duplicate copies of books only partly used. Dr. Munthe points out that European libraries would never make such purchases. ${ }^{3}$

In recent years, little has been written on this subject. Important studies which have been done include: a symposium on problems and procedures at 18 universities, edited by Theodore W. Koch; ${ }^{4}$ an excellent statement of the necessity of the reserve room and methods of making it effective $;^{5}$ and a somewhat more recent treatment by $\mathrm{Harvie}$ Branscomb, ${ }^{6}$ whose dual role as director of libraries and professor of early Christian literature at Duke University enabled him to consider both sides of the question:

The unsatisfactoriness of the reserved book arrangements in most colleges is agreed to by students, librarians and instructors alike.

3 Davidson, Carter. "Book Selection in a Liberal Atts College." In Wilson, L. R., ed. The Practice of Book Selection, p. 243-44. 'Chicago, University of Chicago Press, 1940.

"Koch, T. W., ed. "A Symposium on the Reserve Book System." In Kuhlman, A. F., ed. College and University Library Service: Trends, Standards, Ap. praisal, Problems, p. 73-99. Chicago, American Library Association, 1938 .

5.Kuhlman, A. F. "How Reserve Book Collections SCan Be Made Effective." In his volume cited above,
'Kuhlman, A p. $100-06$.

' Branscomb, Harvie. Teaching with Books: A Study bf College Libraries, Chicago, Association of American Colleges, 1940, p. $57 f f$., $118-31$. 
The brief periods for which the books may be used, the necessity for many duplicates, the waste involved when reading lists are changed, the large number of volumes tied up which are not used, the crowded, noisy and restless condition of the reserved book reading room, and the tendency of students never to go beyond the books given this special handling, are all causes of complaint. ${ }^{\top}$

Recent literature on the subject, far less inclusive than the studies just mentioned, are: Dean Johnson' ${ }^{8}$ analysis of the libraryinstructional program at Stephens College where reserve books are placed in divisional and classroom libraries; the interesting experiment of a college instructor who eliminated his lists of reserved books in advanced history courses, substituting for them bibliographies of books available in the stacks on two-week loan $;^{9}$ and, finally, Miss Rideout' ${ }^{10}$ report on changes in procedure in the reserve room of the University of New Hampshire Library.

The present study is based on a survey of 27 New England college libraries, with five others added for purposes of comparison. "The writer visited one-third of the libraries studied, obtaining statistical information and comments from the remainder by correspondence.

In considering the statistics presented as a part of this report, it is necessary to keep in mind several factors which have a direct bearing upon the figures listed: first, the size of the college or university; second, the type of reserve book service which is provided; third, the differing bases upon which the statistics are compiled. In view of these conflicting elements, we have not attempted to compute statistical averages for

7 Ibid., p. I 18.

8 Johnson, B. L., ed. The Librarian and the Teacher in General Education: A Report of Library-Instructional Activities at Stephens College. Chicago, American Library Association 1948 . 69 .

Library Association, I948. P. 69. "The College Library and Collateral Reading Lists: The Experience of an Historian." College and Research Libraries 8:209-1 3, July I947.

10 Rideout, Jean D. "The University of New Hamp. shire Library Has Worked Out a Reserve Plan." Library Journal 73:643-1 44, April i5, I948. student enrolment, book stock and circulation. The value of such computations is certainly open to question ; methods attempting to eliminate the alleged disadvantages of the reserve room are far more important than mere statistics.

Consequently, turning to procedures being followed in college reserve rooms, we find three standard methods: (1) the closedshelf system (Io libraries-Amherst, Bates, Bennington, University of Connecticut, Holy Cross, the universities of Maine and New Hampshire, Northeastern, Skidmore, and Trinity), whereby all reserve books are kept behind a desk and are passed out over the counter. This has the obvious disadvantage of preventing the student from browsing among the IO, 20 or more books placed on reserve by his instructor; it is most suitable for a reserve room collection consisting chiefly of very heavily-used books. In most cases, loans are limited to two hours plus overnight use; two libraries allow three-day loans: the universities of Connecticut (at the request of the instructor) and New Hampshire. (2) The open-shelf system (five libraries-Bard, Lawrence, Oberlin, Queens, and Wesleyan), in which all books are placed on open shelves around the walls of the reserve room, easily accessible to the students. The latter take books directly from the shelves; therefore, a smaller staff is required in the reserve room. Under this method, books usually may be borrowed for any length of time within the room or within the building; they are charged out only for overnight use; longer loans are made in two cases: Oberlin (seven-day) and Wesleyan (one-day and seven-day). Generally speaking, there is no serious problem of losses from the reserve room using the open-shelf system $;^{11}$ a counter or charging desk is maintained "11 Orr, R. W. "A Few Aspects of College Library
Service." College and Research Libraries 8:340-41,
July 1947. 
Enrolmenc, Book Stock and Circulation

\begin{tabular}{|c|c|c|c|c|c|}
\hline & Enrolment ${ }^{1}$ & $\begin{array}{l}\text { Total } \\
\text { Book Stock }\end{array}$ & $\begin{array}{l}\text { Two-week } \\
\text { Circulation }\end{array}$ & $\begin{array}{l}\text { Reserve } \\
\text { Room } \\
\text { Circulation }\end{array}$ & $\begin{array}{c}\text { Reserve } \\
\text { Room } \\
\text { Book Stock }\end{array}$ \\
\hline $\begin{array}{l}\text { Amherst } \\
\text { Bard } \\
\text { Bates } \\
\text { Bennington } \\
\text { Boston College } \\
\text { Boston Univ.-C.L.A. } \\
\text { Bowdoin } \\
\text { Brown } \\
\text { Clark } \\
\text { Colby } \\
\text { Conn. College } \\
\text { Univ. of Conn. } \\
\text { Dartmouth } \\
\text { Harvard-Widener } \\
\text { Holy Cross } \\
\text { Lawrence (Wis.) } \\
\text { Univ. of Maine } \\
\text { M.I.T. } \\
\text { Middlebury } \\
\text { Mount Holyoke } \\
\text { Univ. of N.H. } \\
\text { Northeastern } \\
\text { Oberlin } \\
\text { Queens } \\
\text { Radcliffe } \\
\text { Skidmore } \\
\text { Springfield } \\
\text { Trinity } \\
\text { Wesleyan } \\
\text { Wheaton } \\
\text { Williams } \\
\text { Yale-Univ. Lib. }\end{array}$ & $\begin{array}{l}1,200 \dagger \\
300 \dagger \\
850 \\
300 \\
3,731 \\
3,961 \\
1,050 \\
4,478 \\
1,100 \\
1,040 \\
834 \\
8,000 \\
2,985 \\
7,487 \\
1,827 \\
1,030 \\
3,790 \\
5,662 \\
1,213 \\
1,196 \\
3,556 \\
3,000 \dagger \\
2,399 \\
3,000 \\
1,365 \\
1,176 \\
1,400 \dagger \\
892 \\
980 \dagger \\
488 \\
1,100 \\
9,017\end{array}$ & $\begin{array}{c}270,000 \dagger \\
60,000 \dagger \\
80,000 \dagger \\
29,136 \\
220,388 \\
100,000 \\
220,000 \\
718,230 \\
178,000 \dagger \\
129,955 \\
112,974 \\
116,000 \\
658,915 \\
2,650,000 \\
146,495 \\
76,000 \\
215,551 \\
417,680 \\
113,750 \\
211,397 \\
153,000 \\
46,000 \dagger \\
472,031 \\
70,000 \\
100,000 \\
62,789 \\
40,000 \\
200,000 \\
338,323 \\
64,273 \\
197,048 \\
2,729,300\end{array}$ & $\begin{array}{r}30,195 \\
22,665 \\
37,565 \\
26,771 \\
40,046 \\
51,091 \\
20,592 \\
77,302 \\
19,155 \\
25,381 \\
29,500 \\
51,676 \\
77,708 \\
264,791 \\
49,771 \\
13,000 \\
93,506 \\
165,691 \\
33,053 \\
29,268 \\
63,766 \\
13,341 \\
152,987 \\
95,320 \\
26,361 \\
84,083 \\
11,000 \\
25,936 \\
51,616 \\
17,912 \\
169,339\end{array}$ & $\begin{array}{c}107,789 \\
13,708 \\
55,376 \\
3,179 \\
8,000 \dagger \\
31,757 \\
24,818 \\
73,147 \\
19,610 \\
9,539 \\
11,836 \\
78,556 \\
183,472 \\
223,517 \dagger \\
16,263 \\
60,513 \\
51,146 \dagger \\
6,120 \\
35,786 \\
8,046 \\
30,955 \\
23,867 \\
54,637 \\
38,380 \\
47,498 \\
6,500 \\
33,734 \\
28,427 \\
58,078 \\
40,556\end{array}$ & $\begin{array}{c}8,736 \\
3,556 \\
2,741 \\
7,387 \\
6,000 \dagger \\
1,007 \\
2,244 \dagger \\
1,000 \dagger \\
4,192 \\
10,722\end{array}$ \\
\hline
\end{tabular}

1 Fall 1947 or 1948.

2 Summer or Fall 1948 .

3 1947-1948.

41947 or 1948

+ Estimated.

near the exit or exits and in most colleges now following this plan there is little complaint on this score. (3) The combination system, incorporating the best features of the first two methods. In this way, heavilyused reserve books are charged out over a counter; all others are on open shelves. This is the most popular system, being followed by the remaining i 7 libraries. Perhaps we should mention, however, that Harvard's Widener Library and the new Lamont Library (of which more later), both now following this plan, will shortly become primarily open-shelf reserve systems. In the combination system, closed reserves are limited to two-hour and overnight use; usually open reserves have unlimited use in the building plus overnight use; in addition, two libraries (Wheaton and Williams) allow one-day use, three libraries (Brown, Clark and Middlebury) have three-day loans, six libraries (Boston University, Bowdoin, Colby, Dartmouth, Mount Holyoke and Springfield) have seven-day loans. In all libraries reporting longer loans, such loans are for collateral reading only; required reading is limited in almost all cases to two-hour and overnight use. It must be remembered, of course, that statistics on building or room use are not usually kept for books on open shelves.

The number of copies provided per stu- 
dent usually varies widely, depending upon: the number of students in the class, the length and purpose of the assignment, the time allowed for reading, and the availability of duplicates. In heavily-used texts, six (Bard, Bowdoin, Colby, University of Connecticut, Queens and Williams) of the I4 libraries reporting on this point provide one copy for every Io students; four libraries (Amherst, Skidmore, Springfield and Radcliffe) provide one for six-eight students; other variations include: Clark (one for five students), Oberlin (one for five-ten students), Dartmouth (one for eight students), University of Maine (one for eight-ten students). The Yale library provides only two copies of any one edition; additional copies must be supplied by the department of instruction.

Most librarians make informal reports on the use of reserve books to the faculty. In five libraries (Brown, Clark, Middlebury, University of New Hampshire and Williams), periodic reports on such use are made. Both formal and informal reports tend to reduce the number of titles placed on reserve. However, only five libraries make a systematic check on reserve-book use. The results were as follows:

\begin{tabular}{l|c|c}
\hline \hline & $\begin{array}{c}\text { Per Cent of } \\
\text { Copies Used Less } \\
\text { Than Nine Times } \\
\text { Per Term }\end{array}$ & $\begin{array}{c}\text { Per Cent } \\
\text { of Copies } \\
\text { Unused }\end{array}$ \\
\hline Colby & $33^{\frac{1}{3} *}$ & $10^{*}$ \\
U. of Maine & $21^{\dagger}$ & $10 \dagger$ \\
Middlebury & 25 & 5 \\
Oberlin & 50 & 10 \\
Queens & 5 & 5 \\
\hline
\end{tabular}

* Approximate.

† Approximate percentage of titles.

Six libraries (Amherst, Bard, Bennington, Dartmouth, Northeastern and Yale) state that the percentage of neglected or unused books would be small. By limiting reserved books to those needed for required reading, less "dead wood" is placed on reserve; where collateral reading is included, the percentage naturally rises.

As for future trends in the college reserve room, we believe that more and more libraries will limit closed reserves as much as possible, placing both required and collateral reading on open shelves. As examples of the smaller colleges, Bard and Radcliffe would like to reduce greatly their reserve collections, returning most of the books to the regular stacks. In the new Hayden Memorial Library, now being built at Massachusetts Institute of Technology, reserve books will be limited, with special reading rooms in English and History. At Yale, most of the reserve collection is already on open shalves. The Widener Library at Harvard, formerly a combination system for undergraduate and graduate students, is now an open-shelf arrangement primarily for graduates.

Harvard's new Lamont Library, beautifully designed in spirit and function, opened its doors to the undergraduates in January, 1949. Its innovations in architectural design, cataloging, classification, and accessibility of books deserve to be closely studied by college and university librarians. At present, 22,000 books and pamphlets, representing approximately one-fourth of the total bookstock, are on reserve. Most of the reserve books are on open shelves in the stacks, arranged alphabetically by author in broad subject classifications such as English, history, philosophy. Each group is as near as possible to the general circulation books in the same field. Closed reserve books are available at two charging desks, located at the entrances to the building. All reserve books may be used for an unlimited time in the building, for overnight and for weekends; general circulation books, also on open shelves, may be used without time limit in the building but are circulated only for one-week loan. All reserve books are intended to be for required reading 
only; collateral reading is near at hand in the regular classification. The number of books on closed reserve will be gradually decreased, being transferred to the open reserve shelves. The Lamont librarian, Philip J. McNiff, emphasizes the fact that the procedural methods now being followed are entirely flexible; they can readily be adjusted to meet changing conditions.

To conclude this study, we shall quote from some of the more interesting comments received through correspondence.

Concerning the matter of reporting on use of reserve books to the faculty, Dr. Felix E. Hirsch, professor of history and librarian, Bard College, states:

I talk the matter over with individual faculty members and use my annual report and occasional circular letters for further discouraging excessive use of reserved books which is contrary to our educational principle (of individualized education).

I might add here that $I$ have fought a losing battle against reserved books. In my earlier days here we had very few of them and at some times I thought I could completely get rid of them, since $I$ believe that in a college with 300 students and 60,000 volumes, under a system of individualized instruction, there is hardly much if any need for reserved books. However, my faculty colleagues proved me wrong and since the end of the war we have been suffering from a reserved book problem which has grown up year by year in spite of all my efforts to the contrary. Probably little can be done about it at the moment, but I hope, as we will have a stabilized faculty eventually again which will be fully familiar with our teaching methods; that the flood of reserved books will recede, as it should.

In speaking of the periodic reports sent to the faculty, David A. Jonah, librarian, Brown University Library, writes that the reaction:

Varies from one faculty member to another. In some cases lists have been cut as much as two-thirds. A year ago when we furnished reports on reserve book use to the faculty, we also sent a letter saying we were not putting on reserve for the coming year books that circulated less than five times. This resulted in about a 50 per cent reduction in desk reserve books for $1947 / 48$. This was not repeated for $1948 / 49$ and it is too early to know whether or not the number going on reserve is increasing.

We would prefer to see reserve books and reserve book rooms done away with and the students either ( $I$ ) required to buy required reading books or else (2) obtain them on a semester rental basis, preferably through the University bookstore. Or a combination of (I) and (2).

B. Lamar Johnson, dean of instruction and librarian, Stephens College, writes as follows:

I fear that we do not have any practices with respect to the use of reserve books that will be of special interest to you. We do have books on reserve shelves in a number of our libraries. Our practice does not, I believe, vary a great deal from that used in most colleges. Perhaps the greatest advantage of our plan over most situations with which I happen to be familiar comes from the fact that our libraries are located adjacent to the offices and classrooms of our respective divisions. This makes it possible for students and faculty together to work with reserve books when this procedure is desirable.

Eileen Thornton, librarian, Vassar College, makes the following analysis of the current reserve book situation there:

You may remember that $B$ ranscomb ${ }^{12}$ was very enthusiastic about our reserve system. He was here, of course, many years ago when the library was not so crowded and when teaching and learning were not under such terrific pressure. The system may well have worked well years ago. I do not believe it does today, and I would like very much to change it. We do not have a reserve room. Reserve books are put on regular shelves all over the building. Most of the time these books are set up in little groups, but sometimes they are left in their regular places according to call number. We may have a separate shelf for each course in the catalogue for which reserve books are used. The theory

$12 O p$. cit., p. $122-24$.

(Continued on page ${ }^{3} 6$ ) 
modules; stack area- 6 modules; conference and seminar rooms -4 modules; staff lounge-I module; offices (order, catalog and periodical checking room) -5 modules; and halls, loan desk, card catalog, stairs and faculty lounge -8 modules.

Each reading room contains cubicles of the conventional type, tables of various shapes and reading room carrels. Some of the cubicles and reading room carrels will be soundproofed with cork to permit typing in the reading rooms. The library plans to rent typewriters.

Bookshelves in the reading rooms will not be dispersed around the walls, but instead will be concentrated, and the reference and reserve books will be located near the reserve and reference desks. The arrangement of furniture and equipment will be informal.

Future expansion will be both vertical and horizontal. Footings permit one full story to be added vertically, and adequate space exists for indefinite horizontal growth.

There is, of course, no one best way to build a library because local needs, traditions, and conditions vary. But where there is a minimum of restricting preconditions, we believe that librarians who need a maximum amount of usable and pleasant working space for each dollar invested, will find a desirable pattern in the library of the North Dakota Agricultural college.

As soon as the building is open for service in the fall of 1950, we invite visitors. In the meanwhile, much information on construction methods can be gained from an onthe-site inspection. Certainly, those who said "it can't be done" will have difficulty in explaining away that which they can see with their own eyes.

\section{Current Trends in the College Reserve Room}

\section{(Continued from page I24)}

has always been that this keeps reserve books close to the other material on the subject. This great faith in the classification scheme astounds me, and even if it were true that the reserve shelf actually lands in the midst of all the other important literature on the subject, I would still feel that this has no particular merit as the students do not have time to shuttle back and forth from reserve books to other books in the course of the day's reading. Last year approximately Io,000 volumes were on reserve during the year.

Like many other librarians, I view the reserve system with a jaundiced eye. In many cases, all that is established is an anthology which does not seem very far from a textbook to me. As our entire library is open shelf, we have no way of knowing how much individual books are used. I am willing to bet, however, that 50 per cent of the books would have served their purposes better from the regular shelves. Pressure does build up for a relatively small number of books and the control of these is extremely difficult. We cannot know about this pressure until the book has been stolen or hidden.

While I hate to revert to the old type of closed reserves, I do wish we could centralize our reserves on open shelves and establish a simple charging system for use in the building as well as for use overnight. ${ }^{13}$

13 The reserve systems of Stephens and Vassar are so atypical that no statistics for these two libraries have been included in this survey. 